\title{
Cattle Grazing White Locoweed: Influence of Grazing Pres- sure and Palatability Associated with Phenological Growth Stage
}

\author{
M.H. RALPHS
}

\begin{abstract}
Understanding the conditions in which livestock consume poisonous plants is necessary to develop management strategies to reduce losses. Three 10 -day grazing trials were conducted to observe consumption of white locoweed (Oxytropis sericea Nutt.) by cattle. The trials corresponded to the phenological growth stages of white locoweed: (1) flower; (2) immature seed pod; and (3) mature seed pod/seed shatter. Six esophageally fistulated Hereford steers were used to collect diet samples. In trial 1, steers selected the locoweed flower only when supplies of grass and other forbs were depleted. In trial 2, steers voluntarily selected the immature pod, which comprised $50 \%$ of their diet by the middle of the trial. There was very little consumption of locoweed in trial 3. Few locoweed leaves were consumed throughout the experiment. Immature locoweed pods were palatable and readily selected by cattle. By restricting access at the immature pod growth stage and insuring adequate forage is available at other times, cattle consumption of white locoweed on this site should be minimized.
\end{abstract}

Key Words: poisonous plant, Oxytropis sericea, silky locoweed, white pointloco

Locoweed poisoning of livestock is the most widespread poisonous plant problem in the western United States (Marsh 1924, James et al. 1981). Several species of the Astragalus and Oxytropis genera have been shown to cause locoweed disease (Marsh and Clawson 1936; James et al. 1981). The alkaloid swainsonine is the principal toxin in locoweed species (Molyneux and James 1982).

White locoweed (Oxytropis sericea Nutt.) is widely distributed (Barneby 1952) and appears to be palatable to horses, sheep, and cattle. Marsh (1909) stated that animals readily eat it in the spring and may continue to do so even when grass is abundant. Animals that eat enough to damage the neurological system and thus become habituated will continue eating it until they die.

There is no antidote for locoweed poisoning. Prevention of poisoning involves preventing livestock from consuming toxic or lethal amounts of the plant. Consequently, understanding the conditions under which livestock consume the plant is essential to reduce losses.

Ralphs et al. (1986) conducted a preliminary study of the utilization of white locoweed on a high mountain range and reported that cattle utilized $36 \%$ of the locoweed standing crop. The reproductive heads were progressively utilized through the grazing season, while the leaves were utilized only during the last 3 weeks of the season. The confounding effects of increasing grazing pressure, possible habituation, and palatability of the different locoweed plant parts at different phenological stages of development; prevented understanding why cattle selected the respective locoweed plant parts. This study was designed to determine the palatability of white locoweed plant parts at different phenological growth stages and assess the role of grazing pressure in cattle selection of white locoweed.

\section{Methods}

The study was conducted during the summer of 1984 on a high

\footnotetext{
Author is range scientist, USDA, Agricultural Research Service, Poisonous Plant Research Laboratory, 1150 East 1400 North, Logan, Utah 84321 .

Journal Paper No. 3255, Utah Agriculture Experiment Station.

Manuscript accepted 22 January 1987
}

mountain grassland in northwestern Utah. The site was a flat mountain top at an elevation of $2,900 \mathrm{~m}$. The range site was a high mountain loam and supported a homogenous grass/forb vegetation community. Dominant grass species included Idaho fescue (Festuca idahoensis Elmer), Muttongrass (Poa fendlariana (Stend.) Vasey), and Kentucky bluegrass (Poa pratensis L.). Dominant forbs included white locoweed, yarrow (Achillea lanulosa Nutt.) and buckwheat (Eriogonum heracleoides Nutt.).

Three 10-day grazing trials were conducted to separate the effects of grazing pressure from palatability of the locoweed plant parts at different phenological growth stages. The trials and corresponding phenological development stages of locoweed were: trial 1-flower stage, July 19-28; trial 2-immature pod stage, Aug. 9-18; trial 3-mature pod/seed ripe stage, Sept.5-14. Three homogenous sites in a rested pasture of the forest allotment were temporarily enclosed with electric fence and randomly assigned to the 3 trials.

Six native yearling Hereford steers that had grazed the site the previous year as calves were esophageally fistulated and used to collect diets. Mean weight of the steers at the beginning of the study was $256 \mathrm{~kg}$. Estimated daily intake was taken from NAS/NRC (1976) requirements based on steer weights and anticipated rate of gain of $0.5 \mathrm{~kg} /$ day; these estimates were then used to estimate total forage required for each trial.

The pasture size was based on the amount of forage required and the available grass standing crop at the beginning of each trial. Pastures contained sufficient grass to last the steers for only 8 days. This limited allocation of preferred forage was designed to increase grazing pressure on desirable forage and force steers to select less preferred species.

Standing crop of grasses, forbs, locoweed leaf and locoweed reproductive head was sampled at the beginning (time 1 ), middle (time 2), and end (time 3 ) of each trial. Five $0.25 \times 1-\mathrm{m}$ quadrats were systematically placed along 5 transects equally spaced in each pasture. A total of 25 quadrats were clipped at each sampling period. The vegetation samples were dried in a forced air open at $60^{\circ} \mathrm{C}$ for $48 \mathrm{hr}$. Samples were weighed and standing crop was calculated as total $\mathrm{kg}$ / pasture. Herbage allowance (HA) was calculated as the ratio of the weight of forage available to the amount of animal demand (kg/steer) at a point in time (Scarnecchia and Kothman 1982). HA of the available grass and total standing crop was calculated at the beginning, middle, and end of each trial.

Diet samples were collected on days $1,2,5,6,9$, and 10 of each grazing trial. Steers were penned at dusk preceding collection days and fasted overnight. We assumed that night grazing on these ranges was negligible. Normally, steers would cease grazing around dusk and would be still lying in the same general area when we arrived the next morning. Thus, penning the steers overnight should not have had much influence on their selective behavior. Penning the steers the night before collections minimized the disturbance of their normal morning grazing activities. The steers were fitted with screen bottom bags at sunrise the day of collection and allowed to graze freely for 30 minutes. The steers were then corralled to remove the bags, and released to graze until the next collection. The diet samples were immediately placed on dry ice and transferred to a freezer for storage. Diet samples were freeze dried and analyzed for botanical composition by the microscope 
Table 1. Standing crop (kg/pasture) and standard errors (in parentheals) of forage claswes by trial and time, forage disappearance and estimated consumption, and herbage allowance (kg/steer) of grass and total standing crop.

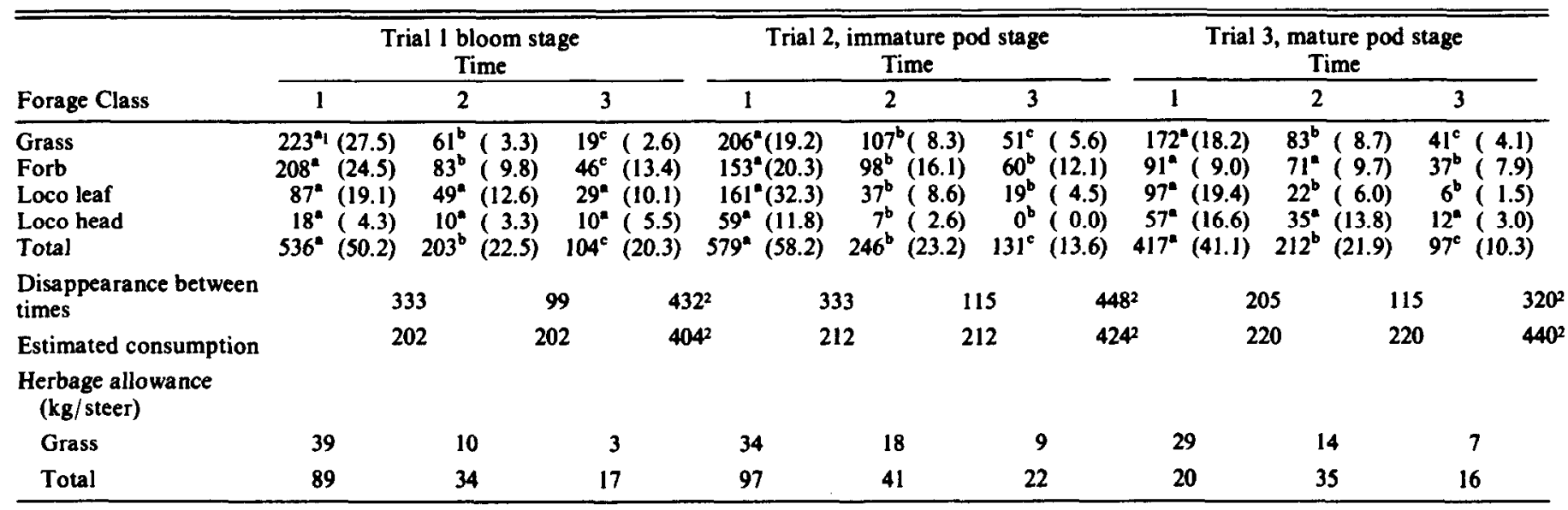

'Means in the same row within trials followed by different letters differ significant ( $P \leq .05$ ) according to Duncan's multiple range test.

2Total disappearance and estimated consumption for the entire trial. Consumption estimated from NAS/NRC (1976) intake tables.

point technique (Harker et al. 1964).

The botanical content of diet samples and forage standing crop were analyzed by analysis of variance (ANOVA) in a split plot design using trial as the main plot and collection period as the split plot. There was a significant trial by time interaction for all parameters analyzed; thus, the model was reduced and the data were analyzed separately for each trial in a one-way ANOVA to determine differences between collection periods.

\section{Results and Discussion}

\section{Diet Samples}

\section{Trial 1.}

There was little change in the botanical composition of steer diets until the last day of the trial (Fig. 1). Grass dominated the

\section{DIET COMPOSITION, TRIAL 1}

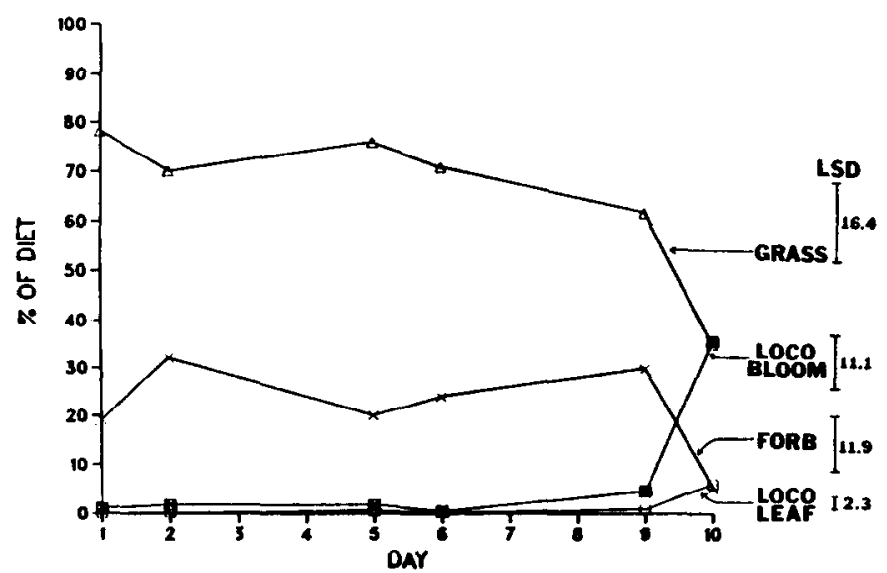

Fis. 1. Diet composition of cattle in trial 1, locoweed bloom stage.

diets $(>70 \%)$ and forbs contributed about $25 \%$. On the last day of the trial, locoweed flowering heads increased to $36 \%$ of the diet, with a corresponding decrease in grasses and forbs. Locoweed leaf also increased to $6 \%$ of the diet. By day 10 of the trial, $91 \%$ of the grass and $78 \%$ of the forb standing crop had been utilized (Table 1). Herbage allowance of grass was $3 \mathrm{~kg} / \mathrm{steer}$ (Table 1), indicating that there was insufficient grass available to meet the steers intake requirements. The steers ran out of desirable forage and started consuming the less desirable locoweed flowering heads. Locoweed flowering heads apparently are not palatable and cattle will not select them if other forage is available.

Trial 2.

Steers began selecting immature locoweed pod (12\% of their diet) on the first day of trial 2 (Fig. 2). Immature pods constituted

\section{DIET COMPOSITON, TRIALL 2}

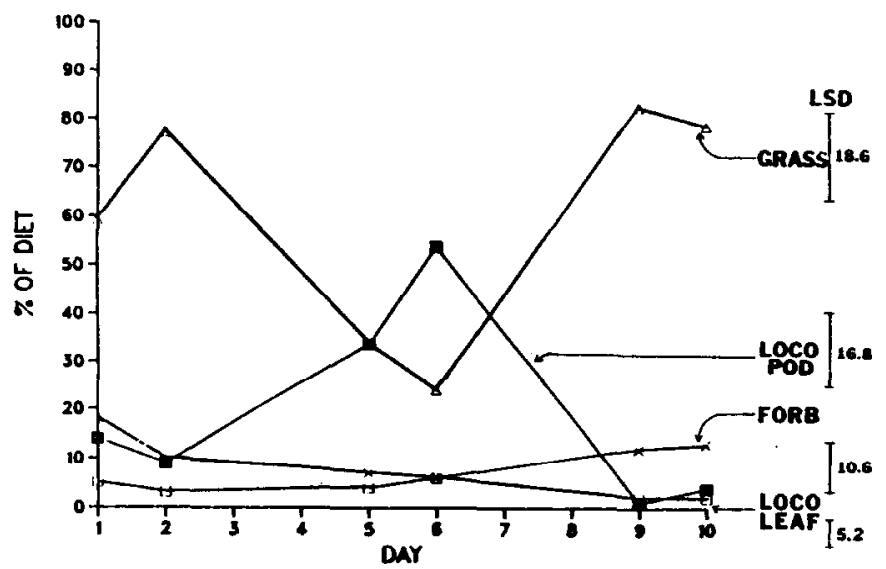

Fis. 2. Diet composition of cattle in trial 2, immature seed pod stage.

$34 \%$ of the diet on day 5 , and $54 \%$ by day 6 . No standing immature pods remained by the end of the trial (Table 1) and the steers reverted to selecting grass. Cattle preferentially selected the immature pods until no pods remained. About half of the initial grass standing crop remained at mid-trial. Herbage allowance of grass was $18 \mathrm{~kg} /$ steer, suggesting that there was sufficient grass available, and hunger did not force steers to select the immature pods. Grazing pressure had little effect on the selection of immature locoweed pods. There was no apparent habituation to the locoweed since consumption of locoweed leaf did not increase after all pods were consumed.

\section{Trial 3.}

Diet selection patterns did not change in trial 3. Grass averaged $80 \%$ of the diets and forbs contributed $14 \%$ throughout the trial (Fig. 3). Little locoweed leaf or pod was consumed.

The selection patterns described in this study were confirmed in a subsequent grazing of free-rangning, intact native and introduced cattle (Ralphs et al. 1987). Cattle consumed no locoweed until 
DIET COMPCSTIION, TRIAL 3

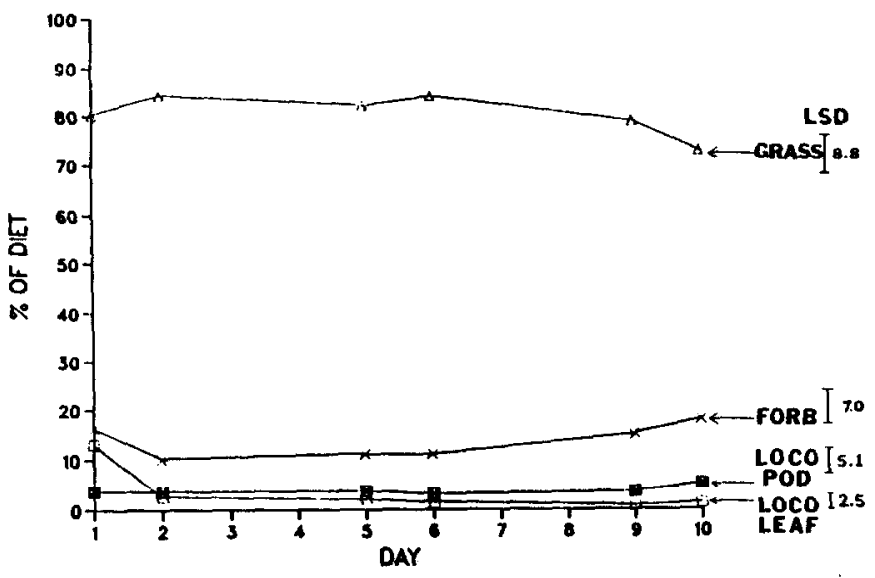

Fig. 3. Diet composition of cattle in trial 3, mature seed pod stage.

the seed pods started developing. A strong preference for the pods was exhibited by both native and introduced cows over an 8-day period. Selection of the pods tapered off as the supply was depleted.

\section{Forage Utilization}

The extremely low herbage allowance was designed to force cattle to graze less desirable forage. The herbage allowance of grass at the end of the 3 trials was less than $10 \mathrm{~kg} / \mathrm{steer}$, compared to 112 $\mathrm{kg} /$ cow for grass and $226 \mathrm{~kg} /$ cow for total standing crop in the subsequent grazing study (Ralphs et al. 1987), where the stocking rate was based on $50 \%$ use of total forage. Despite low herbage allowance in this study, steers did not select significant amounts of the locoweed leaf, mature pods, or flowers. However, the extremely low herbage allowances were brief and did not cause the level of hunger that cattle would experience if the trials were longer.

Total forage disappearance was similar to estimated demand for trial 1 and 2, but was about one-third less than estimated demand in trial 3 (Table 1). The low quality of mature forage may have restricted intake in trial 3 . The largest forage disappearance occurred during the first half of each trial. Disappearance exceeded demand by about $30 \%$ in the first half of the trial but was only $50 \%$ of demand in the last half. Ralphs et al. (1987) also showed that disappearance greatly exceeded estimated demand in the first part of the experiment. In both experiments, cattle either consumed much more forage than the estimated demand at the first of the trials when forage was plentiful, and/or there was substantial trampling damage and nonconsumptive forage loss. Laycock et al. (1972) reported nonconsumptive losses accounted for 50 to $66 \%$ of forage disappearance with sheep grazing mountain range.

Standing crop of locoweed leaf also declined during the first half of trials 2 and 3 (Table 1), although very little locoweed leaf was observed in the diet samples. Disappearance of locoweed leaf may reflect nonconsumptive loss during the first part of the grazing period. Laycock et al. (1972) reported that forbs were particularly susceptible to trampling damage. The upright, pinnately compound loco-leaves could easily have broken off if stepped on.

\section{Conclusion}

The immature seed pod was the only part of the locoweed plant that was palatable to cattle in this study. Cattle preferentially selected immature pods during the first half of the second trial and exhausted the supply. Extremely high grazing pressure, high enough to deplete almost all other forage, was required to force steers to consume locoweed flowers in trial 1 . Steers did not consume significant amounts of the mature seed pod even when grazing pressure was high at the end of trial 3. Cattle consumed little locoweed leaf through the experiment. It appears that cattle will not select significant amounts of locoweed leaves, flowers, or mature pods when adequate forage is available.

Two management strategies are recommended to reduce cattle intoxication from white locoweed on high mountain ranges.

(1) Restrict access to the plant during the immature seed pod phenological growth. If the supply of other desirable forage is adequate, cattle will not be forced to consume the plant at other growth stages.

(2) If cattle must graze pastures when seed pods are immature, stock pastures heavily so immature pods are quickly removed before any one animal consumes enough to become intoxicated. The locoweed toxin is cumulative and high levels must be consumed for at least 2 weeks before signs of neurological damage occur (Van Kampen and James 1970).

\section{Literature Cited}

Barneby, R.D. 1952. A revision of the North America species of Oxytropis D.C. Proc. California Acad. Sci. 4th Series. 27:177-312.

Harker, K.W., D.J. Torell, and G.M. Van Dyne. 1964. Botanical examinations of forage from esophageal fistulas in cattle. J. Anim. Sci. 23:465-469.

James, J.F., W.J. Hartley, and K.R. VanKampen. 1981. Syndromes of Astragalus poisoning in livestock. J. Amer. Vet. Med: Ass. 178:146-150.

Laycock, W.A., H. Buchanan, and W.C. Krueger. 1972. Three methods of determining diet, utilization, and trampling damage on sheep range. $J$. Range Manage. 25:352-356.

Marsh, C.D. 1924. Stock-poisoning plants of the range. USDA Dept. Bull. 1245.

Marsh, C.D. 1909. The locoweed disease of the plains. USDA Anim. Ind. Bull. 112.

Marsh, C.D., and A.B. Clawson. 1936. The locoweed disease. USDA Farmers Bull. 1054.

Molyneux, R.J., and L.F. James. 1982. Loco intoxication: indolizidine alkaloids of spotted locoweed (Astragalus lenriginosus). Science 216:190-191.

NAS/NRC. 1976. Nutrient requirements of domestic animals. Nutrient requirements for beef cattle. 5th revised ed. National Academy of Sciences, Washington, D.C.

Ralphs, M.H., L.F. James, and J.A. Pfister. 1986. Utilization of white pointloco (Oxytropis sericea Nutt.) by range cattle. J. Range Manage. 39:344-347.

Ralphs, M.H., L.V. Mikelsen, and D.L. Turner. 1987. Cattle grazing white locoweed: diet selection patterns of native and introduced cattle. J. Range Manage. 40:333-335.

Scarnechia, D.L., and M.M. Kothmann. 1982. A dynamic approach to grazing management technology. J. Range Manage. 35:262-264.

Van Kampen, K.R., and L.F. James. 1970. Pathology of locoweed (Astragalus lentiginosus) poisoning in sheep. Path. Vet. 7:503-508. 